\title{
Effect of liquid nitrogen cooling on the permeability and mechanical characteristics of anisotropic shale
}

\author{
Long Jiang ${ }^{1} \cdot$ Yuanfang Cheng ${ }^{1} \cdot{\text { Zhongying } \mathrm{Han}^{1} \cdot{ }^{1} \text { Qi Gao }}^{1} \cdot$ Chuanliang Yan $^{1} \cdot$ Huaidong Wang ${ }^{2} \cdot$ Lipei Fu $^{3}$
}

Received: 23 January 2018 / Accepted: 10 June 2018 / Published online: 16 June 2018

(c) The Author(s) 2018

\begin{abstract}
Liquid nitrogen $\left(\mathrm{LN}_{2}\right)$ fracturing is a promising new technology for unconventional reservoir simulation because it can effectively solve problems related to low permeability, low brittleness, and water shortage. The present work conducted a series of permeability and strength property-related experiments to evaluate the effect of $\mathrm{LN}_{2}$ cooling on the permeability and mechanical characteristics of anisotropic shale. The main findings of the study are as follows: (1) The influence of the bedding direction on the permeability of anisotropic shale cannot be eliminated by $\mathrm{LN}_{2}$ cooling. $\mathrm{LN}_{2}$ cooling could effectively increase the initial natural damage and the pore space of anisotropic shale, possibly increasing the volume of reservoir stimulation and provide more channels for the seepage and migration of oil and gas. (2) After $\mathrm{LN}_{2}$ cooling, the strength and brittleness of shale are obviously reduced, leading to the decrease in the ability of shale to resist deformation and failure, thereby helping to decrease the initiation pressure of reservoir stimulation. (3) The brittleness of shale will markedly increase during cryogenic fracturing, thus helping to form more complex fracture networks. Based on the present research, $\mathrm{LN}_{2}$ fracturing has obvious advantages compared with hydraulic fracturing in increasing the volume of reservoir stimulation. The results of this study are instructive for understanding the synergistic mechanism of $\mathrm{LN}_{2}$ fracturing and evaluating the effectiveness of reservoir simulation.
\end{abstract}

Keywords Shale gas $\cdot$ Anisotropic shale $\cdot$ Cryogenic fracturing $\cdot$ Liquid nitrogen $\cdot$ Permeability $\cdot$ Mechanical characteristics

\section{Introduction}

Shale gas, which has become an important unconventional natural gas resource all over the world, has exploitable reserves of approximately $207 \times 10^{12} \mathrm{~m}^{3}$, accounting for $32 \%$ of the total natural gas resources of the world (U. S. EIA 2011; Dong et al. 2012). The effective exploitation and utilization of shale gas are beneficial to increase the supply of clean energy, adjust the energy structure, and alleviate

Yuanfang Cheng

cqj1201311@163.com

$\triangle$ Zhongying Han

2289737064@qq.com

1 School of Petroleum Engineering, China University of Petroleum (East China), Qingdao 266580, Shandong, China

2 CCCC Marine Construction \& Development Co., LTD, Tianjin 300457, China

3 School of Petroleum Engineering, Changzhou University, Changzhou 213016, Jiangsu, China the shortage of oil and gas resources (Qiu et al. 2012; Dong et al. 2012). However, the increase in shale gas production mainly depends on the exploitation of horizontal wells and the development of hydraulic fracturing technology (Middleton et al. 2015; U. S. EIA, 2018). At present, more than $90 \%$ of shale gas wells and $70 \%$ of oil wells are required to carry out large-scale hydraulic fracturing for effective exploitation (Brannon 2010; EIA, 2018), resulting in the explosive growth of hydraulic fracturing applications. Inspired by the global shale gas revolution, China is also successfully conducting shale gas exploration. However, China's shale gas reservoirs have the characteristics of a deep buried depth, large horizontal stress difference, low permeability and low brittleness index, making it difficult to form complex fracture networks after conventional hydraulic fracturing (Jiang et al. 2017). Moreover, as the shale gas reservoirs in China are mainly distributed in water-scarce regions, such as the Sichuan, Tarim, and Turpan-Hami Basins, and large-scale hydraulic fracturing requires the consumption of a large amount of water, hydraulic fracturing cannot be applied in these regions (Li et al. 2016b; Cheng et al. 
2017). Furthermore, the environmental problems caused by hydraulic fracturing, such as the consumption of freshwater resources (Arthur et al. 2009), groundwater contamination (Becklumb et al. 2015), earthquakes (Green et al. 2012), air pollution and clay expansion (Howarth et al. 2011), and storage and treatment of wastewater (Becklumb et al. 2015), has raised significant concerns from many scholars and governments. To meet the special requirements of shale gas exploration to reservoir according to the properties and geological environment, it is the focus of petroleum industry to improve the effect of volume fracturing and identify a substitute for the water-based fracturing fluid (Middleton et al. 2015; Wang et al. 2016). Therefore, many new waterless fracturing technologies, such as liquefied petroleum gas (LNG) fracturing (Lestz et al. 2007), nitrogen foam fracturing (Gupta et al. 1998), liquid/supercritical $\mathrm{CO}_{2}$ fracturing (Gupta et al. 1998; Middleton et al. 2015), and cryogenic fracturing using $\mathrm{LN}_{2}$ (Mcdaniel et al. 1997; Grundmann et al. 1998; Cheng et al. 2017), have been considered by many scholars.

Because $\mathrm{LN}_{2}$ has an extremely low temperature and a high diffusion capacity at room temperature and atmospheric pressure, cryogenic fracturing using $\mathrm{LN}_{2}$ has been considered to be an ideal waterless fracturing technology for shale gas exploration (Li et al. 2016b; Cheng et al. 2017). When $\mathrm{LN}_{2}$ is in contact with rock, the temperature of the rock will drop sharply, thereby inducing a large number of micro-cracks in the interior and surface of the rock due to the non-uniform thermal stress. This approach can obviously improve the pore structure and reduce the bearing capacity of rock. A few experimental studies on cryogenic fracturing using $\mathrm{LN}_{2}$ have been carried out. Mcdaniel et al. (1997) conducted in situ experiments using $\mathrm{LN}_{2}$ in $5 \mathrm{CBM}$ wells, and the results varied: three wells showed increased production, one well showed equivalent production, and one tight sandstone well showed decreased production. Grundmann et al. (1998) exploited a Devonian shale well with $\mathrm{LN}_{2}$ and found that the initial production of the well was $8 \%$ higher than that of conventional fractured wells. Cha et al. (2014) and Alqatahni et al. (2016) also performed laboratory tests on cryogenic fracturing with $\mathrm{LN}_{2}$ and found that $\mathrm{LN}_{2}$ cooling could cause sandstone, concrete and shale to produce many interlaced micro-cracks, and decrease the initiation pressure by $40 \%$. Moreover, Cai et al. $(2014,2015)$ and Cheng et al. (2017) also noted that $\mathrm{LN}_{2}$ cooling can increase the pore connectivity and permeability of shale and coal and reduce their bearing capacity. Although considerable efforts have been made to develop the cryogenic fracturing using $\mathrm{LN}_{2}$, but these studies mainly focused on the change in rock micro-cracks after $\mathrm{LN}_{2}$ cooling, and only a few publications mentioned on the change in the damage characteristics and mechanical properties of rocks. In particular, they did not discuss in depth the influence of $\mathrm{LN}_{2}$ cooling on the seepage and mechanical characteristics of anisotropic shale with different bedding orientations. As we know, shale has strong anisotropy due to the presence of foliation and schistose planes, which seriously affect the change in its pore structure and compressibility after $\mathrm{LN}_{2}$ cooling. Moreover, the influence mechanism of $\mathrm{LN}_{2}$ fracturing is still not completely understood at the bottom of the well. Considering the defects of previous studies, it is of great significance to study the influence of $\mathrm{LN}_{2}$ cooling on the seepage and mechanical characteristics of anisotropic shale.

Accordingly, in this study, cylindrical shale samples with different bedding angles (i.e., $0^{\circ}, 30^{\circ}, 60^{\circ}$ and $90^{\circ}$ ) were used to carry out gas permeability, Brazilian splitting and triaxial compression tests. The influence of $\mathrm{LN}_{2}$ cooling on the permeability and mechanical characteristics of anisotropic shale with different bedding orientations were analyzed based on these experimental results. The study results are expected to provide a fundamental experimental basis for studying the synergistic mechanism of $\mathrm{LN}_{2}$ fracturing and the field application of cryogenic simulation.

\section{Experimental items and testing procedure}

\section{Experimental items}

\section{Gas permeability test}

Permeability, which is widely used to characterize the ability of soil and rock to conduct fluid, is also an important parameter for determining shale gas production. The permeability in rock depends mainly on its porosity, pore size and distribution, pore shape and the arrangement of the pores (AadnØy et al. 2011; Li et al. 2016a). Permeability increases with increasing porosity and grain size, whereas it decreases with the increase in rock compaction and cementation (AadnØy et al. 2011). In this study, gas permeability tests were conducted to measure the gas flow characteristics of anisotropic shale before and after $\mathrm{LN}_{2}$ cooling. Permeability is governed by Darcy's Law, the typical calculation formula is given as follows:

$k=\frac{2 Q \mu L p_{2}}{A\left(p_{1}^{2}-p_{2}^{2}\right)}$,

where $k$ is the permeability of the rock sample $\left(\mathrm{m}^{2}\right) ; Q$ is the gas flow of the rock sample $\left(\mathrm{m}^{3} / \mathrm{s}\right) ; \mu$ is the fluid viscosity (Pa.s); $L$ is the sample length (m); $A$ is the original crosssection area of rock sample $\left(\mathrm{m}^{2}\right) ; p_{1}$ is the gas pressure at the inlet $(\mathrm{Pa})$; and $p_{2}$ is the gas pressure at the outlet $(\mathrm{Pa})$.

\section{Brazilian test}

Brazilian test is often used to measure the tensile strength of rock. In this study, shale has obvious anisotropic characteristics because of the presence of foliation and schistose 
planes; as a result, the traditional isotropic elastic theory is no longer applicable. In the Brazilian tests, the shale is assumed to be a transversely isotropic material. During the tests, it is worth noting that the shale samples should be inclined at four different angles with respect to the corresponding bedding direction, as shown in Fig. 1. In the figure, $\theta$ is the inclination angle between the failure load and the normal direction of the bedding plane $\left(0^{\circ} \leqslant \theta \leqslant 90^{\circ}\right)$. Based on the transversely isotropic elastic theory, Claesson et al. (2002) proposed that the analytical solution of tensile strength can be calculated by the Brazilian test results and the following expressions:

$\sigma_{\mathrm{t}}=\frac{2 P}{\pi D t}\left[\left(\frac{E}{E^{\prime}}\right)^{(1 / 4) \cos (2 \theta)}-\frac{\cos (4 \theta)}{4}(b-1)\right]$

$b=\frac{\sqrt{E E^{\prime}}}{2}\left(\frac{1}{G^{\prime}}-\frac{2 v^{\prime}}{E^{\prime}}\right)$,

$\frac{1}{G^{\prime}}=\frac{1}{E}+\frac{1}{E^{\prime}}+2 \frac{v^{\prime}}{E^{\prime}}$

where $\sigma_{t}$ is the tensile strength (MPa); P is the failure load $(\mathrm{kN})$; D is the sample diameter $(\mathrm{mm})$; $t$ is the thickness of the Brazilian disc (mm); $E$ is the elastic modulus in the transverse isotropic plane (GPa); $E^{\prime}$ is the elastic modulus perpendicular to the transversely isotropic plane (GPa); $G^{\prime}$ is the shear modulus in the plane perpendicular to the transversely isotropic plane (GPa) and is given by Eq. (4) because of the difficulty of measurement (Saint-Venant 1863); and

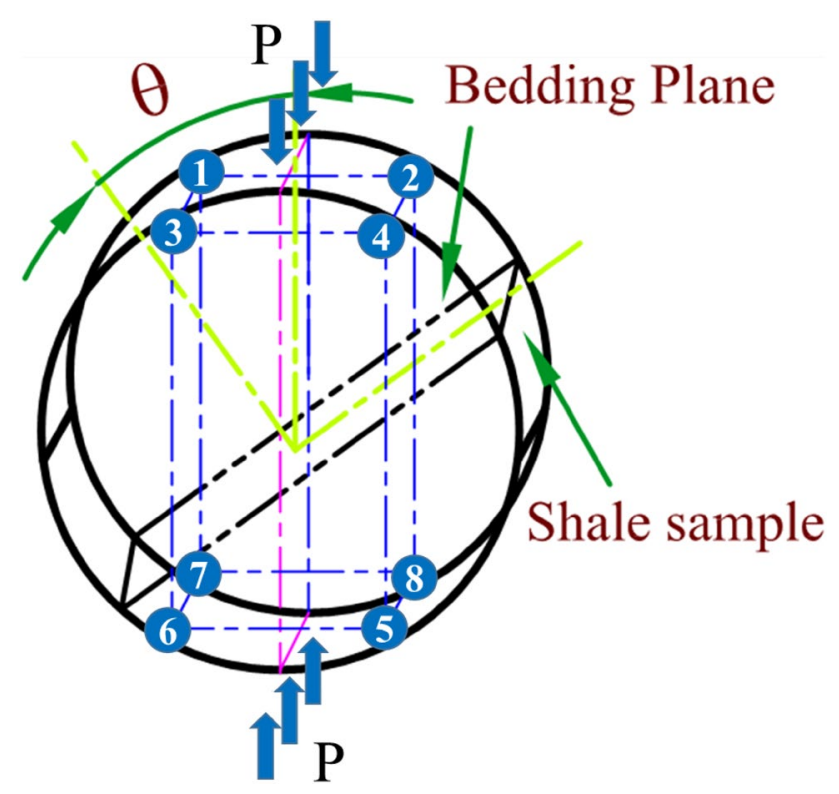

Fig. 1 Loading of shale disc-shaped sample $v^{\prime}$ is the Poisson's ratio perpendicular to the transversely isotropic plane.

From Eqs. (2)-(4), five basic elastic constants were acquired via a series of uniaxial compression tests with different bedding shales according to these references (Amadei et al. 1996; Cho et al. 2012). Table 1 lists the mean value of the transversely isotropic basic elastic constants for the tested shale samples.

\section{Triaxial compression test}

The use of the stress-strain curve of rock is an important method to reflect the mechanical properties of rock material and can fully reveal the deformation and failure characteristics of rock (Cheng et al. 2017; Yan et al. 2015, 2017). In this study, a series of triaxial compression tests were conducted to obtain the mechanical parameters of anisotropic shale; such tests are helpful for evaluating the mechanical characteristics of shale before and after $\mathrm{LN}_{2}$ cooling. Figure 2 shows a TAW-100 servo-controlled triaxial testing system and an assembled shale sample. During the tests, the sample was placed inside the heat-shrink rubber, and the fluid pressure (confining pressure) is applied to its surface. Axial and radial deformations of the specimens were most conveniently monitored by the deformation sensor. Four axial and lateral strains were recorded simultaneously by the axial and lateral strain

Table 1 Basic elastic constants of shale samples

\begin{tabular}{llrlll}
\hline Rock properties & $E(\mathrm{GPa})$ & $E^{\prime}(\mathrm{GPa})$ & $v$ & $v^{\prime}$ & $G^{\prime}(\mathrm{GPa})$ \\
\hline ORUNS & 18.536 & 12.234 & 0.231 & 0.168 & 6.132 \\
DLNTS & 16.456 & 9.584 & 0.235 & 0.171 & 4.985 \\
SLNTS & 12.297 & 8.454 & 0.241 & 0.175 & 4.150 \\
\hline
\end{tabular}

$v$ is Poisson's ratio in the transverse isotropic plane

ORUNS original and untreated shale, DLNTS dry and $\mathrm{LN}_{2}$-treated shale, SLNTS saturated and $\mathrm{LN}_{2}$-treated shale

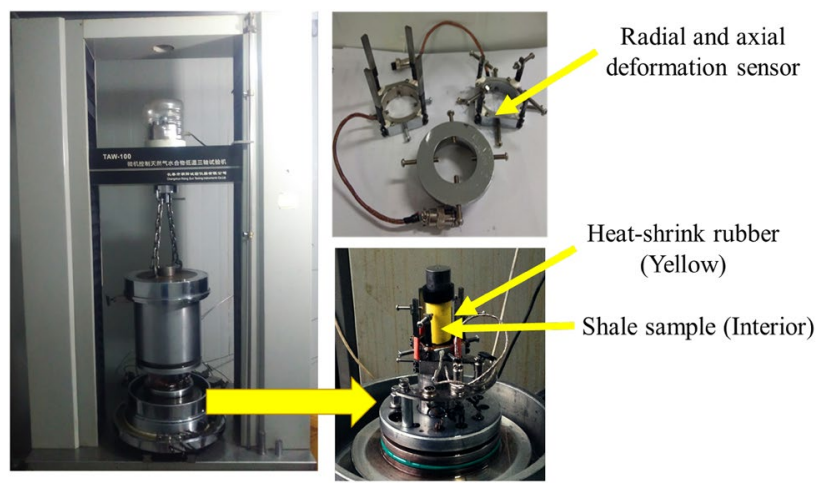

Fig. 2 TAW-100 servo-controlled triaxial testing system and assembled shale sample 
gauges attached to the sample surface. During the compression process, acoustic emission (AE) sensors are applied to monitor fracture initiation and extension in the shale specimens. Then, the stress-strain curves of these triaxial compression tests are recorded. Based on these test results, the influence of $\mathrm{LN}_{2}$ cooling on the energy storage limit and brittleness characteristics of anisotropic shale is also discussed in detail in the following sections.

\section{Sample preparation}

The shale samples studied in the present experiments were obtained from the outcrop of the Silurian Longmaxi formation in Shizhu, Chongqing City, China. The mineral content of the shale was obtained by X-ray diffraction (XRD) analysis, as presented in Table 2. As a type of outcrop shale, natural shale has an initial water content of $15.4 \%$. All shale samples were drilled from the same shale block along 4 different bedding directions. Figure 3 displays the specific core direction, and the dotted lines represent the bedding plane of the shale samples. The bedding angle $\left(\beta=0^{\circ}, 30^{\circ}, 60^{\circ}\right.$ and $\left.90^{\circ}\right)$ is defined as the angle between specimen axis and the layer orientation. According to the International Society for Rock Mechanics standard (Bieniawski et al. 1979; Hawkes et al. 1978), the shale samples were processed into cylinders with $25 \mathrm{~mm}$ diameter and $50 \mathrm{~mm}$ height for the permeability and triaxial compression tests, and Brazilian discs with $25 \mathrm{~mm}$ diameter and $15 \mathrm{~mm}$ thickness were processed for the Brazilian tests. The length and diameter errors of all the specimens are within $\pm 0.5 \mathrm{~mm}$ and their parallelism at the end is within $\pm 0.02 \mathrm{~mm}$ after polishing. Water was not used during sample preparation. To avoid differences among the samples, all drilling samples were screened by magnified observation using a microscope, and the samples without visual cracks were selected as the experimental specimens. In this study, Brazilian tensile specimens were marked as Bi-j, permeability and triaxial compression specimens were marked as $C_{\mathrm{i}-\mathrm{j}}(i=1,2,3$, and 4 represent $0^{\circ}, 30^{\circ}, 60^{\circ}$, and $90^{\circ}$, respectively; $j=1,2$, and 3 represent original and untreated, dry and $\mathrm{LN}_{2}$-treated, and saturated and $\mathrm{LN}_{2}$-treated, respectively).

\section{Experimental procedure}

First, all required cooling samples (i.e., Bi-2, Bi-3, Ci-2 and $\mathrm{Ci}-3$ ) were placed in the drying oven at a constant

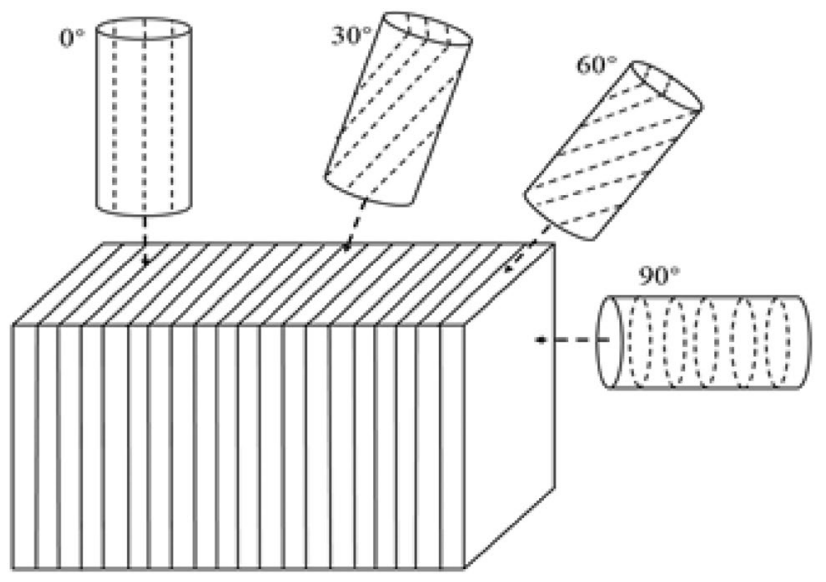

Fig. 3 Directional coring diagram for shale sample preparation

temperature of $60{ }^{\circ} \mathrm{C}$ until fully dried (if the temperature is too high, then the sample will crack.), and the compared samples (i.e., Bi-1 and $\mathrm{Ci}-1$ ) were not dry-treated. Next, gas permeability tests were conducted on all the $\mathrm{Ci}-\mathrm{j}$ samples, and the pressure of the inlet and the outlet of all tested samples were monitored until the inlet pressure remained constant for at least $30 \mathrm{~min}$.

Second, all required water-saturation samples were vacuumed and immersed in distilled water until complete saturation. Next, all required cooling samples were completely immersed in $\mathrm{LN}_{2}$ for half an hour until fully cooled, and the compared samples were not cool-treated. The detailed cooling process can be seen in our previous reports (Cheng and Jiang et al. 2017). After the cooled samples recovered to room temperature, all the treated $\mathrm{Ci}-\mathrm{j}$ samples were again subjected to the similar gas permeability test.

Finally, Brazilian and triaxial compression tests were conducted on all the Bi-j and $\mathrm{Ci}-\mathrm{j}$ samples, respectively, following the International Society for Rock Mechanics standard (Bieniawski et al. 1979; Hawkes et al. 1978). During the Brazilian tests, all the Bi-j samples should be inclined at four different angles with respect to the corresponding bedding direction (see Fig. 1). During the triaxial compression tests, the confining pressure was applied to the $\mathrm{Ci}-\mathrm{j}$ samples via a fluid pressure of $10 \mathrm{MPa}$ (see Fig. 2). The loading rate for both tests was maintained at $0.05 \mathrm{~mm} / \mathrm{min}$.
Table 2 Mineral content of the shale specimen

\begin{tabular}{|c|c|c|c|c|c|c|c|c|}
\hline \multirow[t]{2}{*}{ Quartz } & \multirow[t]{2}{*}{$\mathrm{Pl}$} & \multirow[t]{2}{*}{ Calcite } & \multirow[t]{2}{*}{$\mathrm{Pf}$} & \multirow[t]{2}{*}{ Dolomite } & \multirow[t]{2}{*}{ Pyrite } & \multicolumn{3}{|c|}{ Clay minerals } \\
\hline & & & & & & Chl & Il & $\mathrm{I} / \mathrm{S}$ \\
\hline $54.5 \%$ & $11 \%$ & $6 \%$ & $5 \%$ & $4.5 \%$ & $3.5 \%$ & $1.3 \%$ & $8.93 \%$ & $5.27 \%$ \\
\hline
\end{tabular}

$\mathrm{Pl}$ is plagioclase, $\mathrm{Pf}$ is potash feldspar; $\mathrm{Chl}$ is chlorite; $\mathrm{Il}$ is illite; $\mathrm{I} / \mathrm{S}$ is illite/smectite 


\section{Experimental results and analysis}

\section{Change in the permeability}

Based on the results of previous studies, the better the pore connectivity of rock is, the higher value of permeability, i.e., the ability of rock to conduct fluid increases (AadnØy et al. 2011; Cheng et al. 2017). Figure 4 shows the change in the permeability of different bedding shales before and after $\mathrm{LN}_{2}$ cooling. First, it can be noticed that the permeability of shale always decreases gradually with increasing bedding angle in the three treatment methods. The maximum permeability always occurred at $\beta=0^{\circ}$, and the minimum value ways occurred at $\beta=90^{\circ}$. This result shows that the permeability of shale is influenced by the bedding direction because of the presence of foliation and schistose planes. The direction of the gas flow parallel to the bedding planes will have less impact on its flow capacity, which may be mainly attributed to the connectivity of anisotropic micro-cracks between the layers. Therefore, the permeability parallel to the bedding direction is significantly greater than those in other directions for the three treatment methods. This result reveals that the influence of bedding directions on the permeability of anisotropic shale cannot be eliminated by $\mathrm{LN}_{2}$ cooling. In addition, it can be observed explicitly that the permeability of all $\mathrm{LN}_{2}$-treated samples increases significantly compared with those of original and untreated ones. Moreover, the increase in the permeability of the saturated and $\mathrm{LN}_{2}$-treated samples is greater than those of the dry and $\mathrm{LN}_{2}$-treated ones. For the bedding angles from $0^{\circ}$ to $90^{\circ}$, the permeability of the dry and $\mathrm{LN}_{2}$-treated samples increased by 43.7 , $21.5,25.7$ and $20.2 \%$, respectively; the permeability of the saturated and $\mathrm{LN}_{2}$-treated samples increased by $66.3,50.2$,

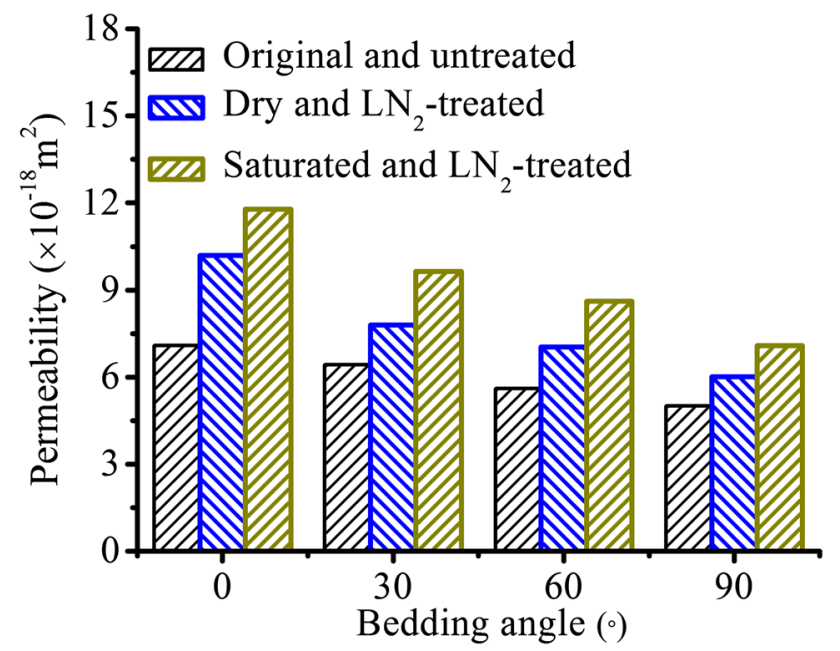

Fig. 4 Permeability of different bedding shales before and after $\mathrm{LN}_{2}$ cooling
53.7, and $41.3 \%$, respectively. The experimental results reveal that the ability of shale to conduct fluid increases dramatically after $\mathrm{LN}_{2}$ cooling. The main reason may be that $\mathrm{LN}_{2}$ cooling induces a large number of micro-cracks and improves the pore size and connectivity in the shale. These micro-cracks provide the main paths for fluid flow, resulting in an increase in the diffusion and migration paths of fluid. Therefore, the permeability of the shale obviously increases after $\mathrm{LN}_{2}$ cooling.

\section{Change in Brazilian tensile strength}

The Brazilian tensile strength (BTS) of shale was obtained using Eqs. (2), in which shale was assumed to be transversely isotropic material. Figure 5 displays the change in the BTS of different bedding shales before and after $\mathrm{LN}_{2}$ cooling. It can be noted from the figure that the BTS of all shale samples always tends to increase with the increasing of bedding angle in three treatment methods. The minimum tensile strength always occurred at $\beta=0^{\circ}$, and the maximum value always occurred at $\beta=90^{\circ}$. Clearly, the tensile strength is affected by the bedding plane normal to the maximum tensile deformation direction. When the load direction was parallel to the bedding direction, the weak bedding planes of shale specimens maintain the maximum tensile stress normal to it, making it easier to generate micro-cracks. During the tests, it could also be observed that the cracks of the original shale samples propagate along the bedding directions at $0^{\circ} \leqslant \beta \leqslant 60^{\circ}$ and along the load direction at $\beta=90^{\circ}$. However, after $\mathrm{LN}_{2}$ cooling, the failure planes obviously exhibited symmetrical crossover along the bedding and load directions at $\beta=90^{\circ}$. This result shows that the effect of $\mathrm{LN}_{2}$ cooling on the strength of bedding weak planes is

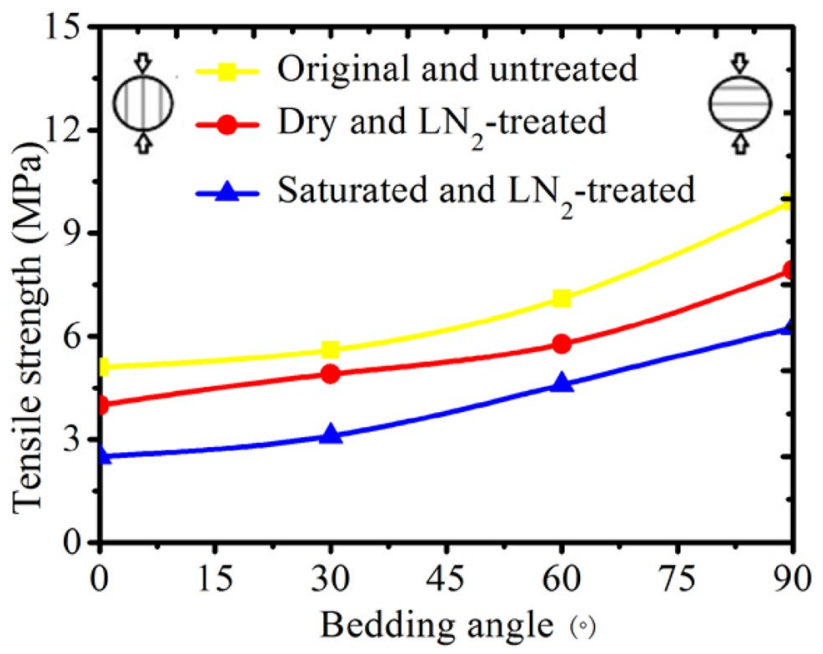

Fig. 5 Brazilian tensile strength of different bedding shales before and after $\mathrm{LN}_{2}$ cooling 
more serious than those of other regions. Comparing the changes in the BTS of the same bedding directions, it was found that the BTS of all bedding directions decreased to different degrees after $\mathrm{LN}_{2}$ cooling, and the BTS of all saturated and $\mathrm{LN}_{2}$-treated samples were lower than those of dry and $\mathrm{LN}_{2}$-treated ones. For the bedding angles from $0^{\circ}$ to $90^{\circ}$, the BTS of the dry and $\mathrm{LN}_{2}$-treated samples reduced by $21.6,12.5,18.6,20.2 \%$, respectively, and the BTS of the saturated and $\mathrm{LN}_{2}$-treated samples decreased by 50.98 , $44.6,35.4,37.1 \%$, respectively. Needless to say, the BTS of $\mathrm{LN}_{2}$ cooling samples is significantly affected by the steep temperature gradient and the degree of hydration. The main reason for the above phenomenon may be that $\mathrm{LN}_{2}$ cooling causes the high shrinkage of dried shale and the frost heaving of water-saturation shale, resulting in the expansion and coalescence of the initial natural micro-cracks and the generation of secondary micro-cracks. Moreover, in the process of water-saturation, when water intrudes into the shale pores, and interacts with the clay minerals, shale will undergo hydration expansion, resulting in the reduction of shale cohesion (Liang et al. 2015). Therefore, the internal structure of anisotropic shale is seriously damaged, resulting in the decrease in its tensile strength.

\section{Change in the stress-strain curves}

A series of triaxial compression tests are performed to study the changes in mechanical characteristics of different bedding shales before and after $\mathrm{LN}_{2}$ cooling. The stress-strain curves of these triaxial compression tests are presented in Fig. 6. The figure shows that $\mathrm{LN}_{2}$ cooling has an obvious influence on the internal structure and deformation behavior of all shale samples. Obviously, all of these stress-strain curves could be divided into four stages. The trend of each stage reveals the effect of $\mathrm{LN}_{2}$ cooling on the micro-structural and mechanical response of anisotropic shale.

Stage I: Crack closure stage. When the specimens were initially compressed, the curves were slightly concave upward. The concave feature of the phase mainly depends on the compaction degree of shale sample. With more

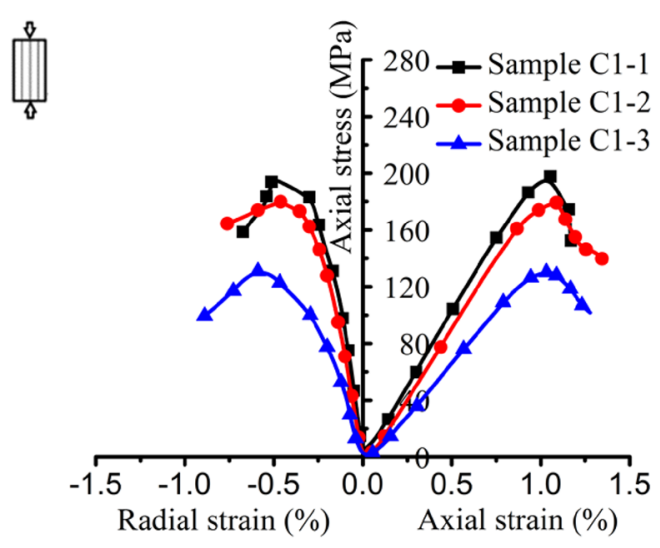

(a)

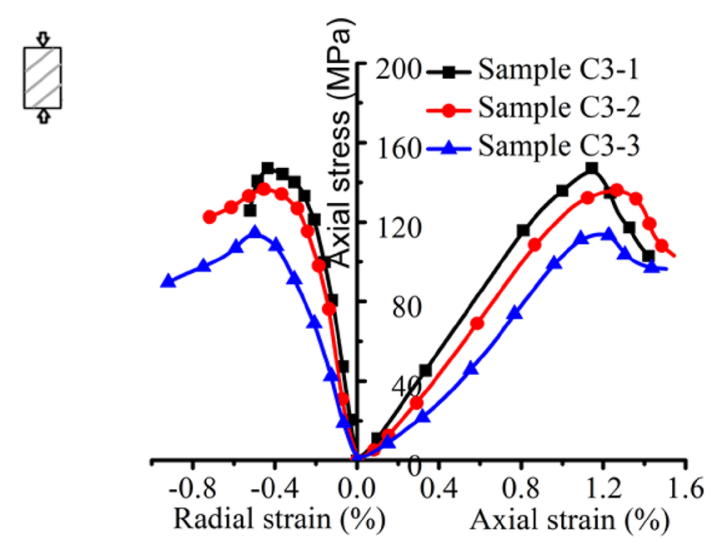

(c)

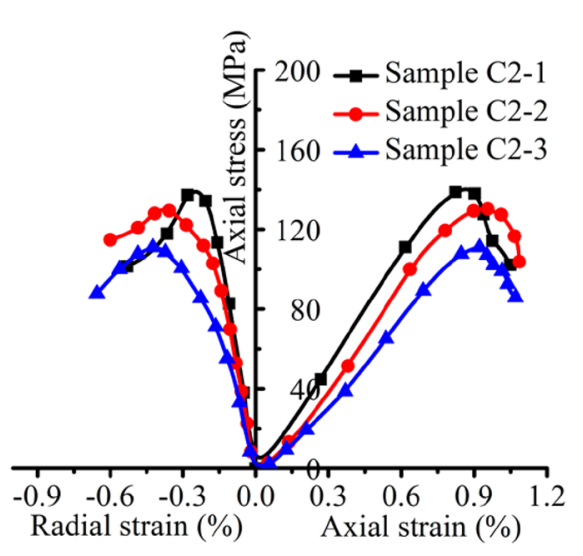

(b)

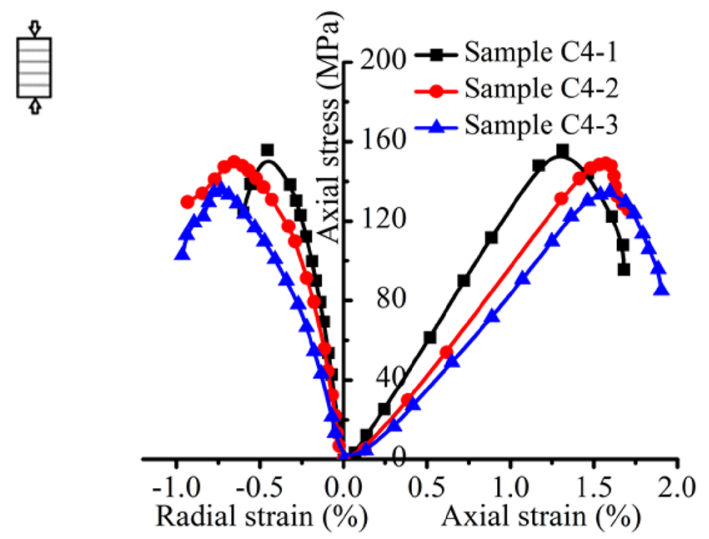

(d)

Fig. 6 Stress-strain curves of different bedding shales before and after $\mathrm{LN}_{2}$ cooling. a $0^{\circ}$ samples, $\mathbf{b} 30^{\circ}$ samples, $\mathbf{c} 60^{\circ}$ samples, $\mathbf{d} 90^{\circ}$ samples 
micro-cracks inside the specimen, the concave feature becomes more obvious. It can be found from the figure that the concavity characteristics of all $\mathrm{LN}_{2}$-treated samples are more obvious than those of the original and untreated ones. The results illustrate that $\mathrm{LN}_{2}$ cooling induces many microcracks and aggravates the initial natural damage of shale.

Stage II: Elastic deformation stage. When the axial loads of these samples reach approximately $15 \%$ of the peak stress, the stress-strain curves begin to approximate a straight line. During this stage, the slopes of the straight lines represent the elastic modulus of each bedded shale sample in the three treatment methods. The greater the number of micro-pores in the shale, the lower is its elastic modulus. The lower the elastic modulus of shale, the worse is its ability to resist deformation (Cheng et al. 2017). It can be seen that the elastic modulus of all $\mathrm{LN}_{2}$-treated samples shows a significant decrease compared with the original and untreated ones. As shown in Figs. 6 and 7, for the bedding angles from $0^{\circ}$ to $90^{\circ}$, the elastic modulus of the dry and $\mathrm{LN}_{2}$-treated samples decreased by $11.2 \%, 10 \%, 11 \%, 22 \%$, respectively, and the elastic modulus of the saturated and $\mathrm{LN}_{2}$-treated samples reduced by $33.7 \%, 25.5 \%, 24.4 \%, 30.9 \%$, respectively. The results reveal that the ability of the shale to resist deformation has been significantly degraded after $\mathrm{LN}_{2}$ cooling. Moreover, the saturated samples exhibited more serious deterioration than the dried samples.

Stage III: Yield stage. When the axial loads of these samples reach approximately $65 \%$ of the peak stress, the stress-strain curves of all specimens become nonlinear again and convex upward until the peak stress, namely, compressive strength. During this stage, the deformation of all samples has significantly plastic characteristics and includes appreciable permanent deformation. A greater number of micro-cracks form, concentrate and connect in the yield

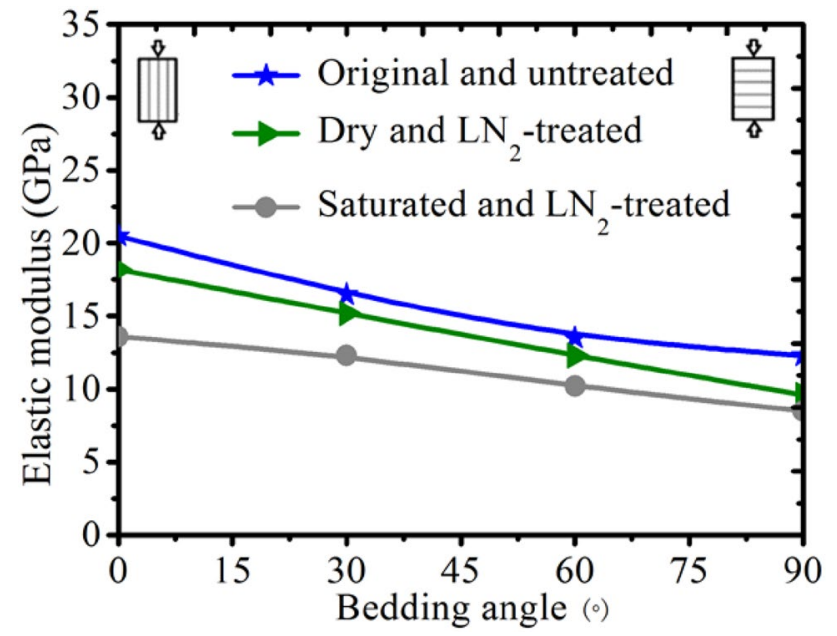

Fig. 7 Elastic modulus values of different bedding shales before and after $\mathrm{LN}_{2}$ cooling stage than in the elastic deformation stage, resulting in a significant increase in the growth rate of damage. Similarly, it can be seen that the compressive strength of all $\mathrm{LN}_{2}$-treated samples shows a significant decrease compared with the original and untreated ones. As observed in Figs. 6 and 8, for the bedding angles from $0^{\circ}$ to $90^{\circ}$, the compressive strength of the dry and $\mathrm{LN}_{2}$-treated samples reduced by $9.3,7.7,7.5$, $4.3 \%$, respectively, and the compressive strength of the saturated and $\mathrm{LN}_{2}$-treated samples decreased by 34.1, 21.4, 32.9, $13.7 \%$, respectively. This result shows that the compressive strength of the saturated and $\mathrm{LN}_{2}$-treated samples are significantly lower than those of dry and $\mathrm{LN}_{2}$-treated ones and indicates that the saturated samples have a greater damage during $\mathrm{LN}_{2}$ cooling. The results reveal that $\mathrm{LN}_{2}$ cooling can effectively reduce the ability of anisotropic shale to resist brittle failure.

Stage IV: Post-peak stage. During this stage, a large number of micro-cracks have been coalesced, all samples show significant macro-failure until complete rupture, and the stress suddenly drops. The change in stress-strain curves of all specimens during this stage can be considered as "the brittle-ductile transition" (Wong et al. 2012; Schöpfer et al. 2013). From the figure, it can be readily noted that the brittleness of the $\mathrm{LN}_{2}$-treated samples is degraded compared to that of the original and untreated ones, and the ductility is slightly increased. The changes in shale brittleness characteristics will be discussed in detail in the latter sections.

During the triaxial compression tests, the failure mechanism of shale can be explained using the sliding crack model of brittle heterogeneous material (Ashby et al. 1990; Li et al. 2015). Figure 9 shows the initial pre-existing microcracks distribution and the sliding crack model of shale samples under triaxial compression. As shown in Fig. 9a, it can be assumed that there are a large number of natural

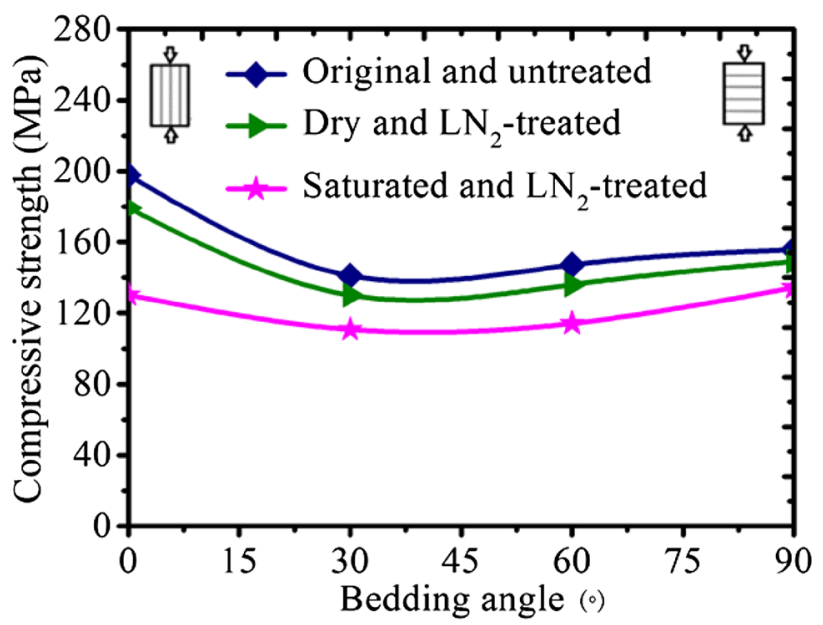

Fig. 8 Compressive strength of different bedding shales before and after $\mathrm{LN}_{2}$ cooling 
micro-cracks and secondary thermal micro-cracks after $\mathrm{LN}_{2}$ cooling inside shale samples; these micro-cracks can be regarded as the pre-existing micro-cracks (see Fig. 9b). When the shear stress in the pre-existing micro-cracks exceeds the frictional force between crack interfaces, the wing cracks will be created from the tips of the pre-existing micro-cracks. Subsequently, a large number of microcracks inside the shale began to expand and connect, and the connection and growth of micro-cracks will lead to a large area of local failure. If the shale samples contain more pre-existing micro-cracks, these cracks will more easily connect, grow and interpenetrate. As observed in Figs. 6, 7, 8 , the ultimate stress levels of all $\mathrm{LN}_{2}$-treated specimens

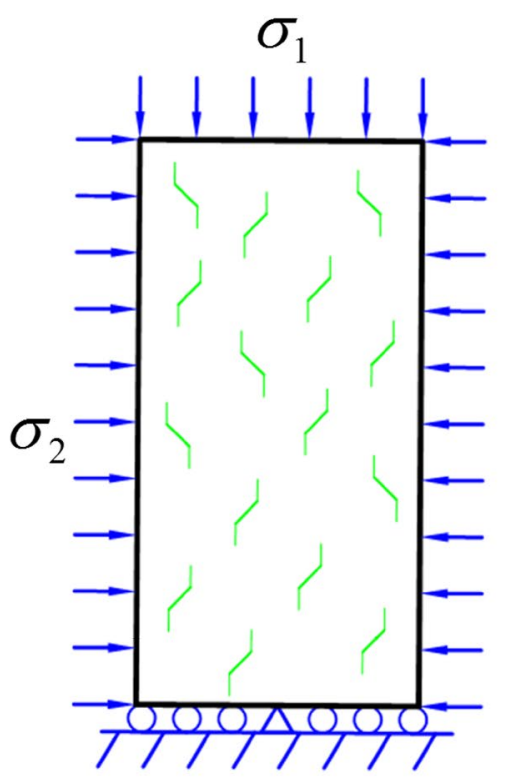

(a)

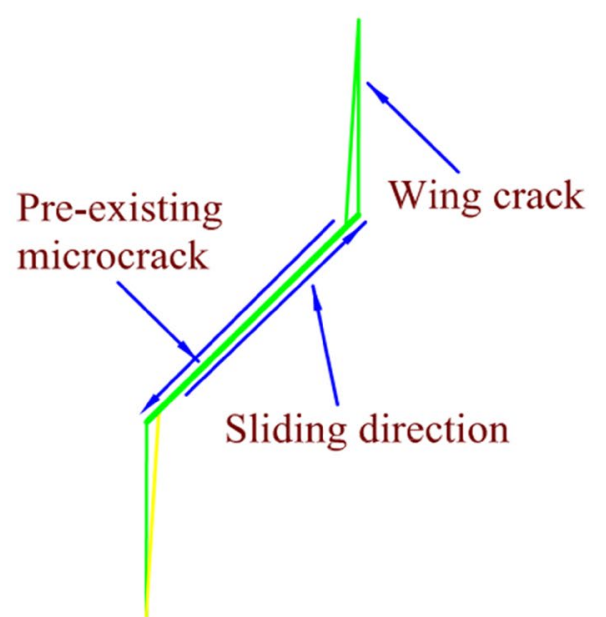

(b)

Fig. 9 Crack growth of shale samples under triaxial compression. a Pre-existing micro-cracks distribution in the shale samples $\left(\sigma_{1}\right.$ is axial stress; $\sigma_{2}$ is confining pressure), b Sliding crack model are significantly lower than those of original and untreated ones, indicating that all $\mathrm{LN}_{2}$-treated specimens contain more the pre-existing micro-cracks than those of the original and untreated samples, resulting in the decrease in its effective bearing area and bearing capacity.

\section{Change in AE characteristics}

The AE release of energy is an important indicator that can fully reflect the occurrence of AE events caused by microfracturing. During the triaxial compression tests, AE sensors are applied to monitor the micro-fracturing in the shale specimens. Figure 10 shows the temporal variations in the axial stress and the $\mathrm{AE}$ events of shale specimens $\left(\beta=0^{\circ}\right)$ under triaxial compression condition. From the graph, it can be observed explicitly that $\mathrm{AE}$ events begin to occur at the middle stress level and increase with the increasing of axial stress. Moreover, the accumulated number of AE events is found to be considerably low before the macrofracture. When the axial stress reaches the peak, the accumulated number of AE events increased steeply up to the main macro-fracture. The phenomenon may be attributed to the ductile deformation of shale samples before the macrofracture. Meanwhile, it can also be observed that the accumulated number of $\mathrm{AE}$ events of $\mathrm{LN}_{2}$ cooling samples is higher than those of the original and untreated one. This phenomenon illustrates that $\mathrm{LN}_{2}$ cooling samples generate more micro-cracks than the original and untreated sample during the entire loading stage, As discussed in the preceding section (see Figs. 6, 8), the peak stress of $\mathrm{LN}_{2}$ cooling samples is lower than the original and untreated ones, and it indicates that the ability of resisting brittle failure of the shale is significantly reduced after $\mathrm{LN}_{2}$ cooling. The results reveal that $\mathrm{LN}_{2}$ cooling aggravated the initial natural damage of the shale, resulting in an increase in the micro-cracks and heterogeneity. Therefore, AE events also significantly

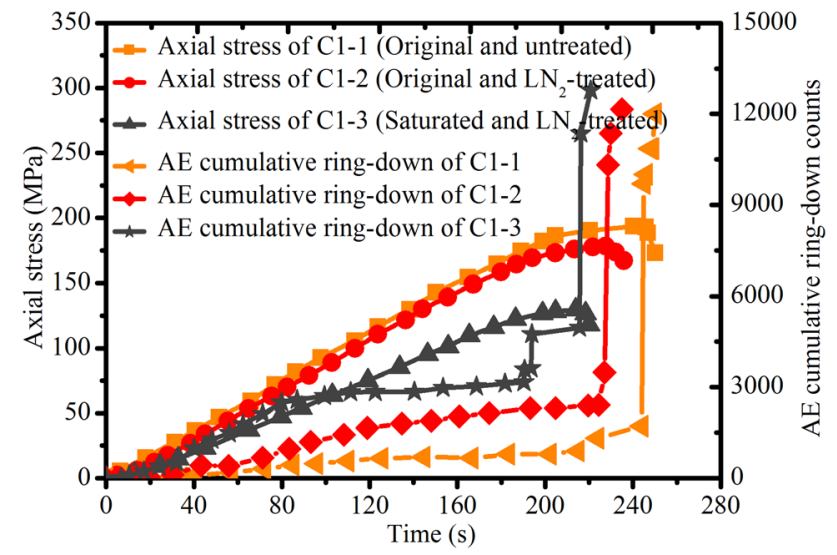

Fig. 10 Temporal variation in axial stress and AE events of shale specimens under triaxial compression conditions 
increase with increasing shale heterogeneity at the same load level because of the effect of $\mathrm{LN}_{2}$ cooling.

\section{Change in brittleness characteristics}

The brittleness of shale can significantly affect the stability of the borehole wall and the effect of reservoir simulation and is considered as a key index to forming complex fracture networks in hydraulic fracturing. In this section, the newly established evaluation method of brittleness involves the stress dropping rate after the peak stress of the stress-strain curve and the ratio of elastic energy release at the point of rock failure to the total energy that stored before the peak stress (Xia et al. 2016); the method can be used to accurately evaluate the brittleness characteristics of shale under complex stress conditions. It can be expressed by the following formulas:

$B=B_{\text {pre }}+B_{\text {post }}$,

$B_{\text {pre }}=\frac{S_{\Delta \mathrm{ABD}}}{S_{\Delta \mathrm{ACO}}}=\frac{(1 / 2) \times|\mathrm{AB}| \times|\mathrm{BD}|}{(1 / 2) \times|\mathrm{AC}| \times|\mathrm{OC}|}=\frac{\left(\sigma_{p}-\sigma_{r}\right)\left(\varepsilon_{r}-\varepsilon_{p}\right)}{\sigma_{p} \varepsilon_{p}}$,

$B_{\text {post }}=\frac{\left(\sigma_{\mathrm{p}}-\sigma_{\mathrm{r}}\right)}{\left(\varepsilon_{\mathrm{r}}-\varepsilon_{\mathrm{p}}\right)}$,

where $B$ is the total brittleness index; $B_{\text {pre }}$ is the pre-peak brittleness index and its range is 0 to $1\left(0 \leqslant B_{\text {pre }} \leqslant 1\right) ; B_{\text {post }}$ is the post-peak brittleness index; $S_{\triangle \mathrm{ABD}}$ is the area of the triangle $\mathrm{ABD}$ that represents the elastic energy released by the unstable failure, as shown in Fig. 11; $S_{\triangle \mathrm{ACO}}$ is the area of the triangle $\mathrm{ACO}$ that represents the total energy stored before the peak strength; $\sigma_{\mathrm{p}}$ is the peak strength; $\sigma_{\mathrm{r}}$ is the residual strength; $\varepsilon_{\mathrm{p}}$ is the peak strain; $\varepsilon_{\mathrm{r}}$ is the residual strain.

Previous studies have confirmed that the brittleness indices of $0^{\circ}$ and $90^{\circ}$ bedding shale samples are greater than

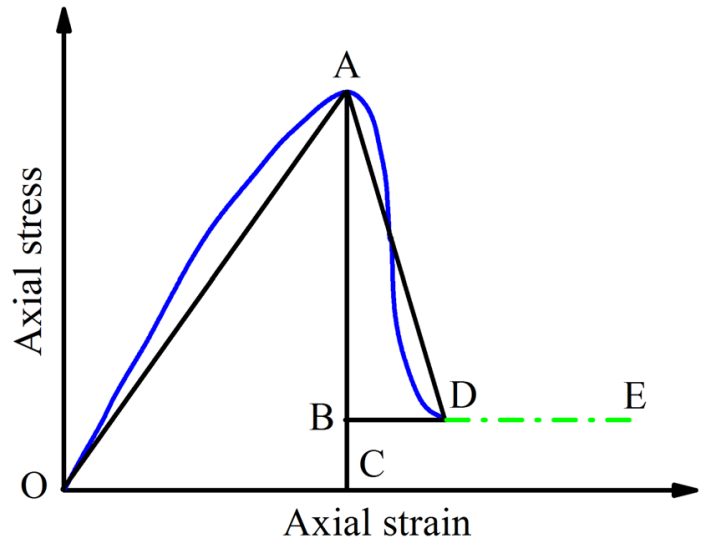

Fig. 11 Schematic diagram for calculating the brittleness index the values of other bedding directions in uniaxial compression tests (Hou et al. 2016). Figure 12 exhibits the changes in the brittleness index of all shale samples with confining pressure of $10 \mathrm{MPa}$ before and after $\mathrm{LN}_{2}$ cooling. From the figure, it can be observed that the brittleness index of the shale always tends to increase substantially with increasing bedding angle in the three treatment methods. Clearly, the brittleness indices of $90^{\circ}$ samples are greater than the values of other bedding directions. Moreover, the brittleness indices of $0^{\circ}$ samples are significantly reduced in this study according to the results of the previous uniaxial compression tests by Hou et al. (2016). It can be believed that the brittle characteristics of shale are mainly affected by the bedding weak plane and confined pressure in triaxial compression tests. During the triaxial compression tests, the lateral deformation of the shale will be limited by the confined pressure, and the bedding weak plane will also be compacted. Limiting the lateral deformation will cause the brittleness of the shale to decrease and the ductility to increase. Compacting the bedding plane of the shale will enhance its internal structure, which in turn will increase its brittleness. Under the low confining pressure of $10 \mathrm{MPa}$, the bedding planes are not obviously compacted, and the lateral deformation perpendicular to the direction of the bedding planes (i.e., $0^{\circ}$ samples) is better constrained, causing the brittleness of the shale in the bedding direction to be quickly reduced. This may be the main reason for the decrease in the brittleness index with confining pressure for the $0^{\circ}$ sample. In addition, it is also worth noting that the brittleness indices of all $\mathrm{LN}_{2}$-treated samples decrease significantly compared with those of the original and untreated ones. Moreover, the decrease in the brittleness indices of the saturated and $\mathrm{LN}_{2}$-treated samples is greater than those of dry and $\mathrm{LN}_{2}$-treated ones. The results indicate that the

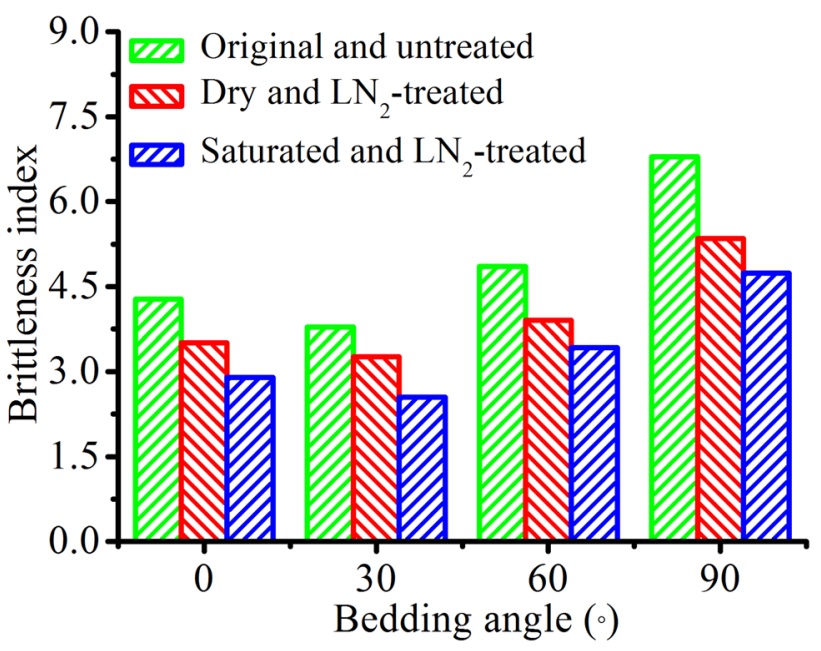

Fig. 12 Brittleness index of different bedding shales before and after $\mathrm{LN}_{2}$ cooling 
brittleness of the shale is significantly reduced after $\mathrm{LN}_{2}$ cooling. It reveals that the brittleness of shale reservoir will be obviously deteriorated after cryogenic fracturing using $\mathrm{LN}_{2}$, thus causing negative effects on its mechanical properties and the stability of borehole. In repeated fracturing, this may affect the effect of multiple episodes of fracturing; this topic should be further discussed in future research. However, during cryogenic fracturing using $\mathrm{LN}_{2}$, the brittleness of the shale will markedly increase because of the effect of water-ice phase transition. It is well known that, when the temperature of the shale samples falls below the freezing point $\left(0{ }^{\circ} \mathrm{C}\right)$ of water, the pore water will freeze into ice lenses. The ice lenses fill the pore space of the shale and can be considered as an adhesive material. The ice lenses has a certain strength and cementing ability among the solid particles (Inada et al. 1984), possibly improving the overall strength and brittleness of the shale. A high brittleness index indicate that the shale is more brittle and is more likely to be broken fully, thereby causing the formation of more channels for oil and gas seepage and migration. Therefore, cryogenic fracturing helps to increase the volume of reservoir stimulation and promote the desorption and diffusion of oil and gas, thus improving the effectiveness of reservoir simulation.

\section{Change in the energy storage limit}

In rock mechanics, the elastic energy and dissipation energy were widely used to analyze the deformation and failure of rock (Wang et al. 2017). The elastic energy is released with the failure of rock, and this process is reversible. The dissipation energy is dissipated by the plastic deformation and internal damage of rock. According to the law of conservation of energy, the total energy, elastic energy and dissipation energy can be calculated by the loading and unloading stress-strain curves of triaxial compression tests, as shown in Fig. 13; they can be respectively defined as follow:

$U^{\mathrm{t}}=\int_{0}^{\varepsilon_{1}} \sigma_{1} \mathrm{~d} \varepsilon_{1}+\int_{0}^{\varepsilon_{2}} \sigma_{2} \mathrm{~d} \varepsilon_{2}+\int_{0}^{\varepsilon_{3}} \sigma_{3} \mathrm{~d} \varepsilon_{3}$,

$U^{\mathrm{e}}=\frac{1}{2 E_{\mathrm{u}}}\left[\sigma_{1}^{2}+\sigma_{2}^{2}+\sigma_{3}^{2}-2 \nu_{\mathrm{u}}\left(\sigma_{1} \sigma_{2}+\sigma_{2} \sigma_{3}+\sigma_{3} \sigma_{1}\right)\right]$,

$U^{\mathrm{d}}=U^{\mathrm{t}}-U^{\mathrm{e}}$,

where $\mathrm{U}^{\mathrm{t}}$ is the total energy density; $\mathrm{U}^{\mathrm{e}}$ is the elastic energy density; $U^{d}$ is the dissipation energy density; $\sigma_{\mathrm{i}}$ is the principal stress $(\mathrm{i}=1,2,3) ; \varepsilon_{\mathrm{i}}$ is the principal strain in the principal stress direction $(\mathrm{i}=1,2,3) ; \mathrm{E}_{\mathrm{u}}$ is the unloading elastic modulus under unilateral cyclic loading and can be replaced by the initial elastic modulus; and $\nu_{\mathrm{u}}$ is Poisson's ratio.

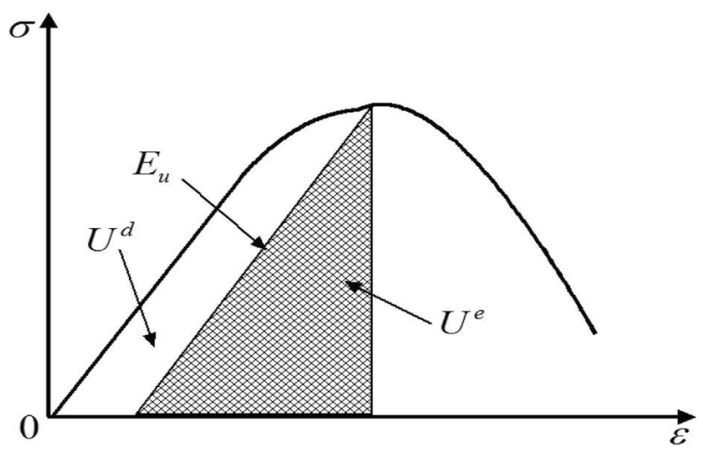

Fig. 13 Relationship between the dissipated strain energy and the elastic strain energy

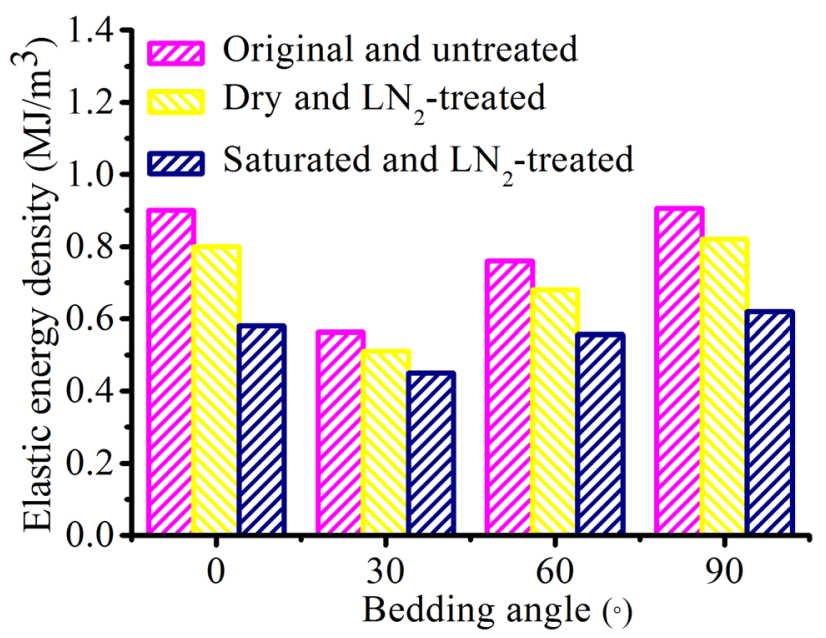

Fig. 14 Energy storage limit of different bedding shales before and after $\mathrm{LN}_{2}$ cooling

In the loading process, the elastic strain energy is stored with the deformation of rock. When the rock is unloaded or destroyed, the elastic energy is released. When the rock reaches the peak strength under triaxial compression conditions, the elastic energy will reach the maximum, which is regarded as the energy storage limit of rock. The energy storage limit is closely related to the internal structure and mechanical properties of rock, such as micro-crack distribution and peak strength. If the number of rock micro-cracks is higher, then the energy storage limit is lower. As shown in Fig. 14, the energy storage limits of anisotropic shale have changed greatly before and after $\mathrm{LN}_{2}$ cooling. For the bedding angles from $0^{\circ}$ to $90^{\circ}$, the energy storage limits of the dry and $\mathrm{LN}_{2}$-treated samples decreased by 11.1, 9.3, 10.5 and $9.4 \%$, respectively, and the energy storage limits of the saturated and $\mathrm{LN}_{2}$-treated samples reduced by 35.5 , 20.7, 26.7 and $31.5 \%$, respectively. The results illustrate that $\mathrm{LN}_{2}$-treated samples contain more micro-defects; thus, their energy storage limits are lower than those of original 
and untreated samples. This can also further reveal that $\mathrm{LN}_{2}$ cooling and hydration aggravate the initial natural damage of shale in these experiments, thereby increasing the number and distribution density of micro-cracks inside the shale, and causing the reduction of the energy storage limit and other properties of $\mathrm{LN}_{2}$-treated samples.

\section{Interpretation and discussion}

Based on the above results, shale has strong anisotropic characteristics, and its mineral composition, complex bedding and natural micro-cracks play a decisive role in the seepage and bearing capacity. Moreover, when $\mathrm{LN}_{2}$ and shale contact each other, the shale will undergo high-speed contraction and frost heaving. The thermal stress and frost heaving pressure have serious effects on the internal microstructure and mechanical characteristics of shale. Therefore, it is necessary to further discuss the damage mechanism of the shale caused by hydration stress, thermal stress, and frost heaving pressure.

When $\mathrm{LN}_{2}$ is in contact with dried shale, the interior of the shale will undergo greater thermal deformation, which results in the uncoordinated deformation between mineral particles due to the heterogeneity of shale micro-structure. During $\mathrm{LN}_{2}$ cooling, the stress concentration will occur at the tip of natural micro-cracks. When the tensile stress inside the shale exceeds the cementation strength of mineral particles, and the shale will produce a large number of micro-tensile cracks. The nucleation and growth of these micro-cracks will further aggravate the damage of the shale during $\mathrm{LN}_{2}$ cooling. As can be seen in Fig. 15, the scanning electron microscope (SEM) images show the propagation of micro-cracks of dried shale during $\mathrm{LN}_{2}$ cooling. It can also be noted from the figure that the mineral particles of the shale are loosely arranged. These mineral particles are cemented each other, and there are many initial natural and secondary thermal micro-cracks. According to the theory of micro-damage mechanics, the large-scale failure of heterogeneous rock can be regarded as the cumulative process of micro-cracks growth (Cheng et al. 2017; Feng et al. 2017). The connection of these micro-cracks will cause greater damage to the shale. Therefore, the initial natural damage of the shale after $\mathrm{LN}_{2}$ cooling is further aggravated.

In addition, the coupled effect of hydration stress, frost heaving pressure and thermal stress has a serious impact on the deterioration of water-saturated shale. The clay minerals content of the shale is $15.5 \%$ (see Table 2). When the shale is immersed in distilled water, the clay minerals exhibit hydration swelling, which generates the hydration stress inside the shale. The hydration stress mainly concentrates at the tip of the micro-cracks and bedding planes, which extends these micro-cracks inside the shale and reduces its cohesive force and internal friction force (Liang et al. 2015). Therefore, the interaction between distilled water and clay minerals will cause the shale to undergo seriously secondary microdamage. During $\mathrm{LN}_{2}$ cooling, the pore water inside the shale will be transformed into pore ice, which will cause a large amount of frost heaving pressure to squeeze the pore wall. Moreover, the temperature will also cause the heat shrinkage. The coupled effect of frost heave pressure and thermal stress will greatly deteriorate the internal micro-structure of the shale. As shown in Fig. 16, the SEM images show the propagation of micro-cracks of water-saturated shale during $\mathrm{LN}_{2}$ cooling. It is clear that many micro-cracks are induced in the frozen shale due to the coupled effect of ice crystallization pressure and thermal stress. Based on the present experimental results, all mechanical parameters of the saturated and $\mathrm{LN}_{2}$-treated samples were lower than those of dry and $\mathrm{LN}_{2}$-treated ones. It can be concluded that the coupled effect of hydration stress, frost heaving pressure and thermal stress can further exacerbate the damage of the shale, thus
Fig. 15 SEM images of dried shale after $\mathrm{LN}_{2}$ cooling (Cai et al. 2014). $\mathbf{a} \times 2500, \mathbf{b} \times 5000$

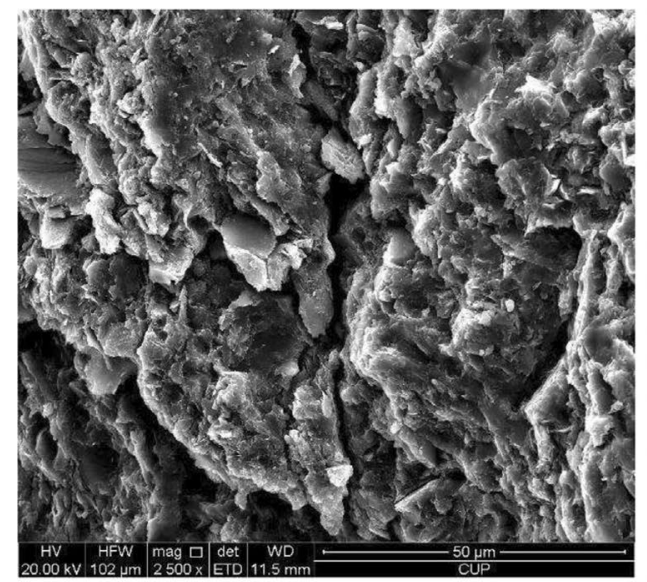

(a) $2500 \times$

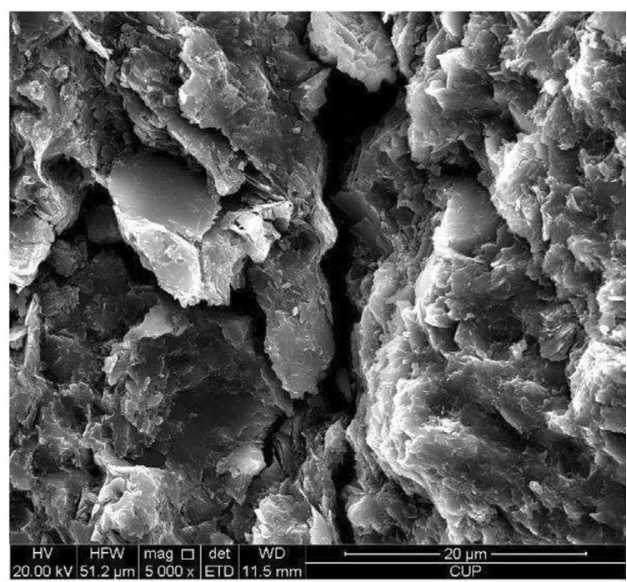

(b) $5000 \times$

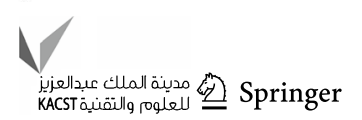




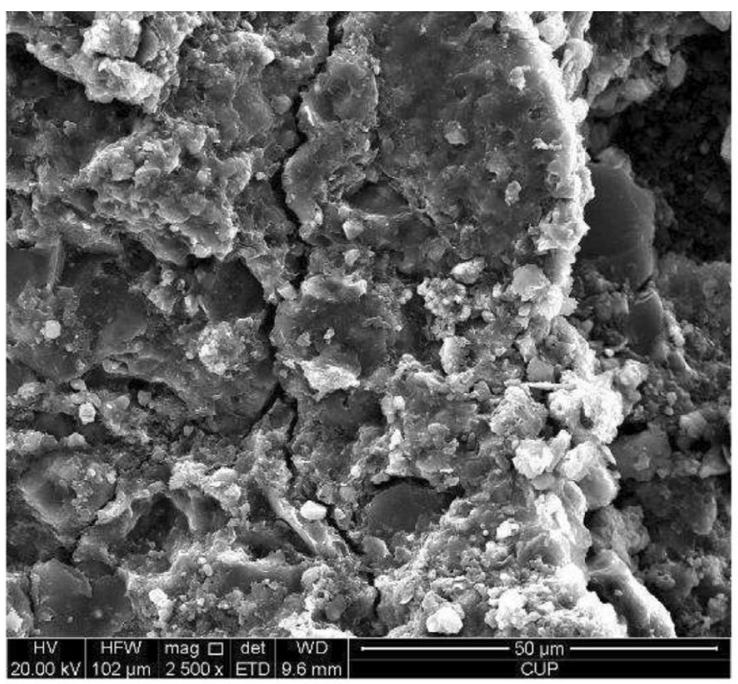

(a) $2500 \times$

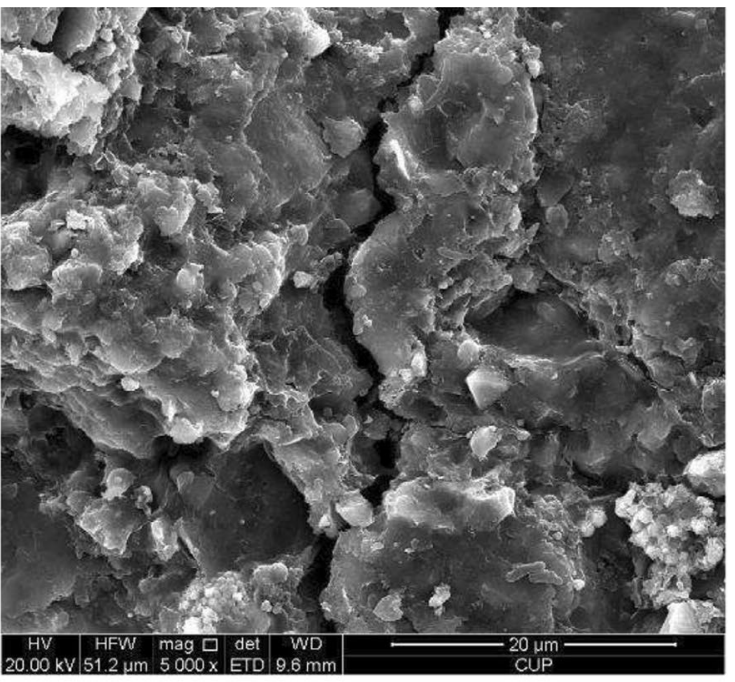

(b) $5000 \times$

Fig. 16 SEM images of water-saturated shale after $\mathrm{LN}_{2}$ cooling (Cai et al. 2014). $\mathbf{a} \times 2500, \mathbf{b} \times 5000$

resulting in a much larger reduction in the mechanical properties and an increasing in the permeability.

In summary, a large number of micro-cracks can be induced by $\mathrm{LN}_{2}$ cooling. These micro-cracks not only provide the main path for fluid flow, but also reduce the effective bearing area of the shale, which results in the decrease in its bearing capacity. Meanwhile, the brittleness of the shale will markedly increase during cryogenic fracturing, which helps to form more complex fracture networks. These results indicate that cryogenic fracturing using $\mathrm{LN}_{2}$ can increase the volume of reservoir stimulation and provide more channels for the seepage and migration of oil and gas, which can greatly improve the production of shale gas in unconventional reservoirs. Based on the present research, $\mathrm{LN}_{2}$ fracturing has obvious advantages compared with hydraulic fracturing in increasing the volume of reservoir stimulation. Besides, as a waterless fracturing technology, $\mathrm{LN}_{2}$ fracturing also has other obvious benefits that have been discussed in detail by our previous report (Cheng and Jiang et al. 2017). But it is also worth noting that $\mathrm{LN}_{2}$ fracturing faces severe challenges, for example, the phase transformation of $\mathrm{LN}_{2}$, antifreezing of the shaft lining, selection of the transfer lines, and the use and migration of the proppant with $\mathrm{LN}_{2}$, and so forth. These topics must be further explored in future research.

\section{Conclusions}

The present experimental study reports the effect of $\mathrm{LN}_{2}$ cooling on the permeability and mechanical characteristics of anisotropic shale. A series of permeability and strength property-related experiments were conducted on Longmaxi shale samples before and after $\mathrm{LN}_{2}$ cooling. The changes in the permeability and mechanical characteristics of the shale after $\mathrm{LN}_{2}$ cooling were analyzed in detail. Based on this study, the following main findings were obtained:

1. The influence of the bedding directions on the permeability of anisotropic shale cannot be eliminated by $\mathrm{LN}_{2}$ cooling. $\mathrm{LN}_{2}$ cooling could effectively increase the initial natural damage and the pore space of shale, thereby increasing the volume of reservoir stimulation and providing more channels for the seepage and migration of oil and gas.

2. After $\mathrm{LN}_{2}$ cooling, the strength and brittleness of anisotropic shale are obviously reduced, leading the decrease in the ability of shale to resist deformation and failure, which helps to decrease the initiation pressure of reservoir stimulation. Moreover, the brittleness of the shale will markedly increase during cryogenic fracturing, which helps to form more complex fracture networks. Laboratory work also showed that the damage of water-saturated shale was greater than that of dried shale during $\mathrm{LN}_{2}$ cooling. It can be concluded that the coupled effect of hydration stress, frost heaving pressure and thermal stress can further exacerbate the damage of shale.

3. Based on the present research, $\mathrm{LN}_{2}$ fracturing has obvious advantages compared with hydraulic fracturing in unconventional reservoir stimulation. However, $\mathrm{LN}_{2}$ fracturing also faces severe challenges, for example, the phase transformation of $\mathrm{LN}_{2}$, antifreezing of the shaft lining, selection of the transfer line, and the use and 
migration of the proppant with $\mathrm{LN}_{2}$, and so forth. These topics must be further explored in future research.

Acknowledgements The authors would like to thank the National Natural Science Foundation of China (Grant Nos. 51574270, 51504280, 51704311 and U1762216), the Changjiang Scholars and Innovative Research Team in University (Grant No. IRT_14R58) for their financial support. Many thanks to anonymous colleagues for their kind efforts and valuable comments in improving this paper.

Open Access This article is distributed under the terms of the Creative Commons Attribution 4.0 International License (http://creativeco mmons.org/licenses/by/4.0/), which permits unrestricted use, distribution, and reproduction in any medium, provided you give appropriate credit to the original author(s) and the source, provide a link to the Creative Commons license, and indicate if changes were made.

\section{References}

AadnØy BS, Looyeh R (2011) Petroleum rock mechanics: drilling operations and design. Gulf Professional Publishing, Oxford

Alqatahni NB, Cha MS, Yao BW, Yin XL, Kneafsey TJ, Wang L, Wu YS, Miskimins JL (2016) Experimental investigation of cryogenic fracturing of rock specimens under true triaxial confining stresses. In: SPE Europec featured at 78th EAGE conference and exhibition, 30 May-2 June, Vienna, Austria. SPE-180071-MS

Amadei B (1996) Importance of anisotropy when estimating and measuring in situ stresses in rock. Int J Rock Mech Min Sci Geomech Abstr 33(3):293-325

Arthur JD, Bohm BK, Cornue D (2009) Environmental considerations of modern shale gas development. In: Presented at the SPE annual technical conference and exhibition, 4-7 October, New Orleans, Louisiana. SPE-122931-MS

Ashby MF, Sammis CG (1990) The damage mechanics of brittle solids in compression. Pure Appl Geophys 133(3):489-521

Becklumb P, Chong J, Williams T (2015) Shale gas in Canada: Environmental risks and regulation. economics, resources and international affairs Division, Ottawa, Canada, Publication No. 2015-18-E. https://lop.parl.ca/content/lop/Research Publicatio ns/2015-18-e.html\#a20

Bieniawski ZT, Bernede MJ (1979) International Society for Rock Mechanics Commission on standardization of laboratory and field tests: Suggested methods for determining the uniaxial compressive strength and deformability of rock materials. Int J Rock Mech Min Sci Geomech Abstr 16(2):138-140

Brannon HD (2010) Hydraulic fracturing materials: application trends and consideration. In: Proc. SPE Distinguished Lecture Program Society of Petroleum Engineers Richardson TX

Cai CZ, Li GS, Huang ZW, Shen ZH, Tian SC, Wei JW (2014) Experimental study of the effect of liquid nitrogen cooling on rock pore structure. J Nat Gas Sci Eng 21:507-517

Cai CZ, Li GS, Huang ZW, Tian SC, Shen ZH, Fu X (2015) Experiment of coal damage due to super-cooling with liquid nitrogen. $\mathrm{J}$ Nat Gas Sci Eng 22:42-48

Cha MS, Yin XL, Kneafsey TJ, Johanson B, Alqatahni NB, Miskimins JL, Patterson TW, Wu YS (2014) Cryogenic fracturing for reservoir stimulation-laboratory studies. J Petrol Sci Eng $124: 436-450$

Cheng YF, Jiang L, Wang HD, Ansari U, Han ZY, Ding JP (2017) Experimental study on pore structure and mechanical properties of stratified coal. Int J Geomech 17(12):04017116
Cho JW, Kim H, Jeon S, Min KB (2012) Deformation and strength anisotropy of Asan gneiss, Boryeong shale, and Yeoncheon schist. Int J Rock Mech Min Sci 50:158-169

Claesson J, Bohloli B (2002) Brazilian test: stress field and tensile strength of anisotropic rocks using an analytical solution. Int J Rock Mech Min Sci 39:991-1004

Dong DZ, Zhou CN, Yang H, Wang MY, Li XJ, Chen GS, Wang SQ, Lü ZG, Huang YB (2012) Progress and prospects of shale gas exploration and development in China. Acta Petrolei Sinica 33(S1):106-114 (in chinese)

Feng YC, Gray KE (2017) Modeling lost circulation through drillinginduced fractures. SPE J. https://doi.org/10.2118/187945-PA

Green CA, Styles P, Baptie BJ (2012) Preese Hall shale gas fracturing review and recommendations for induced Seismic Mitigation. Department of Energy and Climate Change, London

Grundmann SR, Rodvelt GD, Dials GA, Allen RE (1998) Cryogenic nitrogen as a hydraulic fracturing fluid in the Devonian shale. In: Presented at the SPE Eastern Regional Meeting, pp 9-11 November, Pittsburgh, Pennsylvania. SPE-51067-MS

Gupta B (1998) The history and success of liquid $\mathrm{CO}_{2}$ and $\mathrm{CO}_{2} / \mathrm{N}_{2}$ fracturing system. In: Presented at the SPE Gas Technology Symposium, 15-18 March, Calgary, Alberta, Canada. SPE-40016-MS. https://doi.org/10.2118/40016-MS

Hawkes I, Bieniawski ZT (1978) International Society for Rock Mechanics Commission on standardization of laboratory and field tests: Suggested methods for determining tensile strength of rock materials. Int J Rock Mech Min Sci Geomech Abstr 15(3):99-103

Hou ZK, Yang CH, Wei X, Wang L, Wei YL, Xu F, Wang H (2016) Experimental study on the brittle characteristics of Longmaxi formation shale. J Chin Coal Soc 41(5):1188-1196 (in Chinese)

Howarth RW, Santoro R, Ingraffea A (2011) Methane and the greenhouse-gas footprint of natural gas from shale formations. Clim Change 106(4):679-690. https://doi.org/10.1007/s1058 4-011-0061-5

Inada Y, Yokota K (1984) Some studies of low temperature rock strength. Int J Rock Mech Min Sci Geomech Abstr 21(3):145-153

Jiang TX, Bian XB, Wang HT, Li SM, Jia CG, Liu HL, Sun HC (2017) Volume fracturing of deep shale gas horizontal wells. Gas Ind., http://www.cnki.net/kcms/detail /51.1179.TE201702 20.1522.022.html. (in press, in Chinese)

Lestz RS, Wilson L, Taylor RS, Funkhouser GP, Watkins H, Attaway D (2007) Liquid petroleum gas fracturing fluids for unconventional gas reservoirs. J Can Petrol Technol 46(12):68-72. https://doi. org/10.2118/07-12-03

Li XZ, Shao ZS, Wang XY (2015) Research into the effects of micromechanical parameters on creep failure in brittle rocks. Arab J Geosci 8(10):7763-7769

Li MH, Yin GZ, Xu J, Cao J, Song ZL (2016a) Permeability evolution of shale under anisotropic true triaxial stress conditions. Int J Coal Geol 165:142-148

Li ZF, Xu HF, Zhang CY (2016b) Liquid nitrogen gasification fracturing technology for shale gas development. J Petrol Sci Eng 138:253-256

Liang LX, Xiong J, Liu XJ (2015) Experimental study on crack propagation in shale formations considering hydration and wettability. J Nat Gas Sci Eng 23:492-499

Mcdaniel BW, Grundmann SR, Kendrick WD, Wilson DR, Jordan SW (1997) Field applications of cryogenic nitrogen as a hydraulic fracturing fluid. In: Presented at the SPE annual technical conference and exhibition, 5-8 October, San Antonio, Texas. SPE 38623-MS

Middleton RS, Carey JW, Currier RP, Hyman JD, Kang QJ, Karra S, Martínez JJ, Porter ML, Viswanathan HS (2015) Shale gas and non-aqueous fracturing fluids: opportunities and challenges for supercritical $\mathrm{CO}_{2}$.. Appl Energy 147:500-509

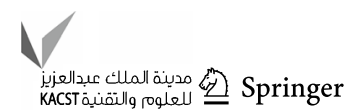


Qiu ZJ, Deng ST (2012) Strategic position of unconventional natural gas resources in China. Nat Gas Ind 32(1):1-5 (in Chinese)

Saint-Venant B (1863) Sur la distribution des élasticités autour de chaque point d'un solide ou d'un milieu de contexture quelconque, particuliérement lorsqu'il est amorphe sans être isotrope. J Math Pures Appl 7-8:353-430 257-261 (In France)

Schöpfer MPJ, Childs C, Manzocchi T (2013) Three-dimensional failure envelopes and the brittle-ductile transition. J Geophys Res Solid Earth 118(4):1378-1392

U.S. Energy Information Administration (2011) Shale gas and the outlook for U.S. natural gas market and global gas resources. U.S. Department of Energy, Washington, DC. http://www.eia.gov/repor ts. Accessed 16 January 2018

U.S. Energy Information Administration (2018) Hydraulically fractured horizontal wells account for most new oil and natural gas wells. U.S. Department of Energy, Washington, DC. https://www.eia. gov/naturalgas/. Accessed 16 Jan 2018

Wang L, Yao BW, Cha MS, Alqatahni NB, Patterson TW, Kneafsey TJ, Miskimins JL, Yin XL, Wu YS (2016) Waterless fracturing technologies for unconventional reservoirs-opportunities for liquid nitrogen. J Nat Gas Sci Eng 35:160-174

Wang P, Xu JY, Fang XY, Wang PX (2017) Energy dissipation and damage evolution analyses for the dynamic compression failure process of red-sandstone after freeze-thaw cycles. Eng Geol 221:104-113

Wong TF, Baud P (2012) The brittle-ductile transition in porous rock: a review. J Struct Geol 44:25-53

Xia YJ, Li LC, Tang CA, Ma S, Li M, Bao CY (2016) Rock brittleness evaluation based on stress dropping rate after peak stress and energy ratio. Chin J Rock Mech Eng 35(6):1141-1154 (in Chinese)

Yan CL, Deng JG, Hu LB, Chen ZJ, Yan XJ, Lin H, Tan Q, Yu BH (2015) Brittle failure of shale under uniaxial compression. Arab J Geosci 8(5):2467-2475

Yan CL, Deng JG, Cheng YF, Li ML, Feng YC, Li XR (2017) Mechanical properties of gas shale during drilling operations. Rock Mech Rock Eng 50(7):1753-1765 